\title{
A LIGHT SNOW-FALL AFTER FROST
}

ON the flat road a man at last appears:

How much his whitening hairs

Owe to the settling snow's mute anchorage, And how much to a life's rough pilgrimage,

One cannot certify.

The frost is on the wane, And cobwebs hanging close outside the pane Pose as festoons of thick white worsted there, Of their pale presence no eye being aware

Till the rime made them plain.

A second man comes by;

His ruddy beard brings fire to the pallid scene:

His coat is faded green;

Hence seems it that his mien

Wears something of the dye

Of the berried holm-trees that he passes nigh.

The snow-feathers so gently swoop that though

But half an hour ago

The road was brown, and now is starkly white,

A watcher would have failed defining quite

When it transformed it so.

Near Surbiton 